\title{
Can the failure speak? Militant failure in the academy
}

\begin{abstract}
:
Academia is rife with structural issues. We are witnessing a mental health crisis among staff and students, hiring and employment practices are institutionally sexist and racist, and staff are increasingly expected to be a triple threat (research, teaching, and admin superstars). In the face of this discussion of failure can reveal an important fallibility and demystify academic processes. But done badly it can also be self-indulgent and demoralising for those who view themselves as failures. Exhortations from those that have been successful to stick at it and be more resilient do nothing to combat the serious issues that (early career) academics face. This new focus on failure can only be successful if it is collective not individualising and it retains a focus on the structural. Grounded in my own experiences and anxieties, this intervention argues that a commitment to militant research practices can help us achieve this important task, and that discussions of failure need to consider teaching and not just fieldwork and writing processes. If not, nothing will change and we will continue to fetishise and paradoxically reward people who can 'fail up', while further silencing and alienating those whose 'failures' are more systemic.
\end{abstract}

\section{Key words:}

Failure; militant research; strategic incompetence; methodology 
Try again. Fail again. Fail better.

-Samuel Beckett, "Worstword Ho!"

Consistently misused, Beckett's fundamental absurdism is increasingly lost in the quotation's ubiquity and memeification, with 'failure' synonymous with 'resilience' and central to tedious managerialism. This intervention contends that an academic embrace of 'failure' is necessary but not sufficient. We need to think carefully about not just how we fail, but how we discuss this failure, and, potentially most importantly, who discusses it. Uncritical discussion of failure (re)produces intersectional academic hierarchies, individualising and pathologising rather than developing structural critiques. To ensure that we 'fail better' we must remain attuned to the political economy of the anxiety-inducing academy (Berg et al, 2017), and theorise failure critically, collectively, and carefully as resistance (Halberstam, 2011). As things stand, however, talk of (and in particular, publications on) 'failure' can discipline and demoralise. Not everyone gets to fail in the same way, and not everyone gets to tell the story of their failure, with the voices of those who 'fail up' often the loudest.

This intervention focuses on my own feelings and experiences of failure through three 'cuts': methodological failure, a failure to write, and failures in teaching. While the majority of academic work focuses on the first, increasing informal discussion of the second exists. I argue that care is needed when discussing both kinds of failure as despite best intentions they can actually increase anxiety. Beyond this focus, however, discussion of teaching failures are rare. Not only does this oversight reinforce teaching's undervaluation 
Can the failure speak? Militant failure in the academy

in academia, but, given that early 'career'1 academics teach a disproportionate amount, again these accounts of failure can be alienating. To combat this we not only need to talk about failure more broadly, through different media (i.e. beyond peer-review), and to different audiences, but fundamentally we need to discuss it differently. We must be critical, vigilant, and reflexive when framing our 'failures'. The intervention starts with a focus on militant methodologies, and how, on the one hand, the shame and anxiety that stem from failing to be 'militant' in academia are significant and underplayed. But on the other, the idea of 'militant research' contains the tools that can help us truly fail better, ensuring we focus on the collective not the individual.

\section{Militant research, militant failure}

Most recent geographical discussions of failure explore fieldwork (e.g. Harrowell et al., 2018), showing how methodological failure is both commonplace and generative. Speaking with students and colleagues, and reflecting on my own experiences, this work is invaluable. An omertà has been broken. No longer are methodologies ludicrously perfect; the research process has been demystified. It is clear that things go wrong, and equally that this is fine. As an even more naïve and anxious postgraduate student, this literature reduced some of my own fieldwork stresses and the shame that followed, when things had not gone as planned. Nevertheless, one common theme among this work is redemption-a strong narrative arc where failures were overcome, as both research and researcher improved accordingly. Similarly, despite claims to the contrary, a feeling remains that 'failure' is sanitised - something I am certainly guilty of myself (Author, 2017). While we have moved

\footnotetext{
${ }^{1}$ Although people who 'fail' may end up not having an academic career.
} 
Can the failure speak? Militant failure in the academy

beyond a euphemistic 'messiness', it is worth considering whether these really are examples of 'failure'.

Less common, however, is work that discusses failure within specifically radical, militant, or activist methodologies (cf. Pusey, 2018). When planning my PhD research, I was instead confronted with macho stories of success at the barricades, stories that romanticised the research process and confirmed activist credentials. But, as debates in this journal have shown, there are additional anxieties when attempting explicitly transformative research (Klocker, 2015). On the one hand, these approaches are participatory, breaking down barriers between researcher and researched. Consequently, when they do fail, you have let down yourself and everyone else. And on the other, the researcher's heightened emotional and political investment in the research means that feelings of shame are truly overwhelming - you are not only a failed researcher, but also a failed activist. For me, therefore, the prospect of such an approach placed me in a bind: I was a failure if I did not try, and if I did try I was likely doomed to failure. Despite this, I argue that militant approaches to research can conceptualise and discuss failure productively.

The Argentine research group Colectivo Situaciones (2007) developed the idea of militancia de investigación. With an intentional dual meaning, this concept is understood as both 'militant research' and 'research militancy'. The former focuses on outputs, seeking to co-produce transformative, radical, and structural critiques that help movements, while the latter refers to the research process itself, ensuring that it is critically reflexive, confronting its own tensions and antagonisms, moving dialectically against-and-beyond itself, and never settling on a fixed and comfortable notion of what research militancy should be. Militancia 
Can the failure speak? Militant failure in the academy

de investigación is thus prefigurative, with commensurate means and ends, and therefore while necessary, 'radical' research outputs alone are insufficient. Critical, collective discussion of failure must be central to militant approaches, facilitating this openly dialectical, reflexive movement, including not just how we fail, but also how we talk about it. As I have argued elsewhere, this creates possibilities for research that is militant (Author, 2017).

But to be truly militant requires a commitment to honestly exploring how, why, and whether we have 'failed'. Most obviously I was able to repurpose my 'failure' into an acceptable methodology for my PhD and a methods paper-once again, a narrative of redemption, reiterating the point that failure inevitably leads to better research practice. But this was a highly selective story. And while no untruths were told in the paper, the precarious, early-career-induced publishing pressures meant it was certainly neatened up, and the pay-off exaggerated. Beyond this, however, my ability to 'fail' creatively needs unpacking.

First, that ability stemmed from having time in 'the field'. Without the privilege of a funded PhD this would have been impossible. With less money or time, failure would not have been an option, and I would have been forced into a 'safer' methodology. The extra commitment to militancy would have been too much, the supposedly increased creativity and heightened reflexivity would not have emerged, and the failure, far from glorious, would have been mundane at best. Now, as a precarious academic, the prospect of extended fieldwork seems utopian. Any (typically hypothetical) research time is so short that it forces instrumental methodological approaches, where the prospect of failure is a luxury. 
Can the failure speak? Militant failure in the academy

Second, and relatedly, there were a series of intersectional, structural privileges that enabled me to 'fail' like this. Being a white, able-bodied, cis man helped me access 'elite' participants, and while I repurposed this into a form of militantly 'studying up', such weaponisation of failure is not open to everyone. It is much easier for certain people to 'fail up', who are then commended for their simultaneous honesty and creativity. For others, discussion of failure is much riskier, potentially consolidating pre-existing, discriminatory stereotypes.

Third, the reasons behind the failure need to be explored. While in part this came from a desire to be properly reflexive and, in keeping with militancia de investigación, coproduce original, useful, and radical knowledges, feelings of timidity and anxiety played a significant role. But there is a fine line between diffidence and self-indulgence, with the knowledge that I would resolve my fieldwork dilemmas stemming from the reduced pressure that was placed on 'failure', given the reasons discussed above. Open and honest discussion of mental health challenges during fieldwork is a must, and is thankfully becoming more common (Caretta and Jokinen, 2017), but the ability to repurpose and mobilise these for academic capital is not open to everyone, even if the temptation may be.

A truly militant discussion of failure needs to include non-redemptive failures. We need to go beyond the euphemistic and suspiciously tidy. There need to be more honest discussions about emotions of anxiety and shame that come from attempting (and failing at) all methodological approaches, but in particular those that are explicitly participatory and militant. That said, done badly such confessional accounts can be eye-rolling at best, and downright offensive at worst, with a level of dullness and hubris perfected by a specific subset of white men. Such accounts also need to exist beyond the peer-reviewed article 
Can the failure speak? Militant failure in the academy

because, as the next section explores, this can create further emotional turmoil for those who feel they are failing, but not successful enough to enter the debate. Informal workshops and anonymous, non-peer-reviewed, accessible discussions of failure can be productive, allowing for honesty and inclusiveness that limit the extractive nature of 'failing up' (see Peake and Mullings, 2019).

\section{Failing to write? Or writing about failure?}

While the majority of peer-reviewed work on failure is methodologically focused, many more informal discussions have explored writing for publication and funding bids. A move towards CVs of failure is the most obvious example, with senior academics laying bare the challenges and failures that they have faced (and typically overcome). Likewise there has been an increase in the sharing of reviewers' comments, seeking collective solace through these horror stories. There are very good reasons for both approaches. They can demystify academia's more abstruse processes, and sharing such comments on Twitter taps into important support networks, helping confirm that a lack of success is commonplace, and eliciting positive comments.

But despite these good intentions, I have often found the consequences to be quite the opposite. When faced with the scale of rejection that so many successful scholars have experienced, the idea that it can happen to even stellar academics makes me further convinced that it will happen to me. For example, fellow precariously employed academics and I were discussing paper rejections with a supportive, more senior colleague when they told us about the long list of rejected papers they had endured. Undoubtedly meant in solidarity, this story just increased my anxiety: the prospect of even having written that 
Can the failure speak? Militant failure in the academy

many papers in the first place seemed unattainable, but to then have the confidence to submit them?

These feelings are made worse by sharing horror reviews, where my first thought is not "ah, this can happen to the best of us", but "why the hell would someone feeling so fragile put themselves through that?" In fact, the consequence of reading such reviews is that I become convinced mine will look the same, to the extent that reviewers' comments cause such anxiety that I initially refuse to open them, waiting for a time I am feeling more confident. This is often weeks or months later, meaning that I have occasionally missed deadlines for resubmission; sharing negative comments exacerbates this cycle. So rather than seeing successful colleagues' rejections as a great leveller, ${ }^{2}$ I felt I was even failing at failing. Similarly my colleagues' testimony about their repeated failed applications for research funding has made me even more terrified by the knowledge that to remain in academia I too will have to undertake this seemingly fruitless, needlessly cruel endeavour. The effects/affects of talking about failure are thus not always helpful. I expand on this through two further points.

The first is about humble bragging. When I (and, from a number of conversations, others) read that someone has had their third application for funding rejected in a year, many emotions are elicited. Sympathy is, of course, at the forefront, yet the shame and resignation described above are close behind. But there is also an undercurrent of frustration at these declarations' performativity. Not only can they lapse into a typically male, performative busyness (cf. Graeber, 2018), but the cumulative effect is weirdly

\footnotetext{
${ }^{2}$ Also, rather than just sharing negative reviews, why not collectively change our reviewing practice to be kind and supportive?
} 
Can the failure speak? Militant failure in the academy

disciplinary: yet again, I am not even good enough to fail. People talking about how they are lacking the time to finish off their book (or even that their book contract has been kicked back) remind me that the prospect of a book or semi-coherent proposal seems ludicrous. These CVs of failure become another terrain on which to compete, with the perverse consequence that those best at failing are the most successful.

And it is in this way that discussions of failure can most come to resemble vacuous, platitudinous misunderstandings of Beckett. The morals of the stories tend to be 'stick at it', with the assumption that things will all come good. But they might not, and for many people they never will. Such statements almost simplistically praise the power of positive thinking, which has rightly and roundly been critiqued (Halberstam, 2011). Done badly, therefore, discussions of failure (re)produce troubling 'resilience' discourses. Rather than collectively developing structural critiques of the academy's gendered and racialised political economy (Maddrell et al., 2019), talk of failure can individualise. ${ }^{3}$ Not everyone is in a position to have staying power, nor should this be demanded. The ridiculous expectations placed on most (early career) academics are just that: ridiculous. These should not be normalised - nor should they be perversely fetishised through performative busyness - but instead critiqued. The failure is systemic and not individual and this point can be lost. We must be militant and reflexive in how we frame 'failures', always being aware of our own privileges, and in particular thinking about who can really claim to have failed.

\section{Low end theory}

\footnotetext{
${ }^{3}$ There is, of course, a tension at the heart of this intervention. Its reflexive and personal nature inevitably tends towards the individualising, and the challenge is thus to move from these experiences to develop structural critique. It is precisely this move that is central to militant research.
} 
Can the failure speak? Militant failure in the academy

The normalisation of failure discourse is thus ambivalent. Parallels can perhaps be drawn with the rapid uptake of 'decolonisation' in the academy which, despite being a vital imperative, has seen its meaning blunted through uncritical ubiquity, potentially doing more harm than good (Essen et al., 2017). Much as decolonisation is not mere metaphor (Tuck and Yang, 2012), failure is more than euphemism. Work from aesthetics, where failure has been critically theorised and, importantly, queered (Halberstam, 2011), can avoid this cooption. Here, failure is not just something that is experienced, reflected upon, and written about, but instead a strategy of precarity-driven refusal, central to the dismantling of intersecting, hierarchical structures of domination. Being properly militant about failure thus requires more than simply adding in a tokenistic discussion to pre-existing ways of writing that, all too often, favour masculinist theoretical grandstanding. This can be disrupted, however, with a focus on 'low theory': "a counterhegemonic form of theorizing, the theorization of alternatives within an undisciplined zone of knowledge production" (Halberstam, 2011: 18). 'Low theory' is intentionally messy. It operates across registers, being playful yet caustic in its theoretical iconoclasm, and by failing to reflect dominant academic tropes, can itself be a radical refusal.

It is this commitment to more empirically driven, humble work that Jenny Pickerill (2019) flags as key to a necessary but nascent experimental impulse in geography, arguing that 'low' and 'minor' theory (cf. Katz, 2017) are central to pushing back against citation metrics. A tension exists here, however. As Pickerill herself has documented brilliantly this work is often deemed less good or important - for instance, ranking lowly in both internal 
and external Research Excellence Framework (REF) reviews ${ }^{4}$ - and could be said to be a failure. For those of us towards the low end of the academic hierarchy there is, therefore, a risk to writing such things, as a tantalising end to precarity is linked to publishing in highimpact journals and producing good REF returns, requiring not only a level of confidence, but also often certain styles of writing and theoretical engagement. ${ }^{5}$ The prospects and experiences of failure make such writing simultaneously more daunting and more necessary. In this sense it is harder for those at the bottom to fail militantly, needing to tidy up our experiences for that redemptive pay-off. Consequently it becomes easier for people less likely to be deemed failures to talk more critically about their failure. A collective commitment to low theory may therefore be an important first step, but can also only function with structural reform, as the low end of academia makes it a fundamentally riskier prospect. These tensions arise, in part, from the amount of time many of us at the bottom spend teaching.

\section{Teaching failure}

Conspicuously absent from most discussion of failure is teaching, an oversight as problematic as it is indicative. In the UK context at least, those earlier in their 'careers' often piece together small bits of teaching, regularly across a number of institutions. Or for the lucky ones with full-time contracts, these may well be teaching only/focused or simply contain a disproportionate amount of teaching offloaded by more senior colleagues. Teaching is thus the (quite literally) overwhelming reality for many junior academics, and

\footnotetext{
${ }^{4}$ I have experienced this myself, with my methodological paper on failure being ranked far lower than other work in an internal REF review, despite being my most useful teaching resource, and the paper I am least unhappy with.

${ }^{5}$ Amusingly, or depressingly, this is something else I have failed at. Following advice I once attempted to write in a REF-friendly style, playing up an article's contribution and its rigour, originality, and significance. This infuriated the reviewers and a significant rewrite ensued.
} 
Can the failure speak? Militant failure in the academy

yet, despite accounting for well over $90 \%$ of geography departments' income, it is consistently undervalued - itself a systemic failure. Although lip service is paid to teachingfocused jobs and career paths being valued equally, the reality is completely different. The lack of open discussion of teaching failure therefore has a range of consequences.

First, it reinforces the idea that research is of more value than teaching. Second, it does not reflect the realities of those early in their 'careers', inadvertently reminding them that they are failures for failing to fail in the correct way. Third, it limits the very helpful resources that would come from collective, open, and honest discussions of teaching failure. Given that junior academics typically carry out extremely high teaching loads, often with relatively little experience, this is an issue. It is extremely daunting addressing hundreds of students - especially the first handful of times you do it. Sympathetic testimony from those in a similar situation, discussing what did and did not work, tips for dealing with common issues, and how to cope with 'failures' such as negative student feedback ${ }^{6}$ would be incredibly helpful. Such resources do exist, but tend to be in private support groups on Facebook, or in Twitter conversations - reiterating the value of alternative academic networks (Peake and Mullings, 2019). Taking 'failure' in teaching more seriously, and putting it on a par with failure in research and writing, would be an important step in challenging academic hierarchies, and help those for whom the stakes are much higher when it comes to actually failing.

\footnotetext{
${ }^{6}$ With thanks to Reviewer 2 who raised an excellent point about success and failure when teaching as an academic-militant. 'Success' tends to be couched in highly instrumental and problematic metrics - metrics that both staff and student unions have boycotted - that are themselves gendered and racialised. Yet, as someone on a precarious contract, there is pressure to play the game, and thus the necessary push-back against these metrics must come from more secure, 'successful' colleagues.
} 
Can the failure speak? Militant failure in the academy

Once again, however, care must be taken in how this failure is framed and discussed. Bad teaching is home to the most tedious of the humble brags. We all know and recognise these people: the staff who take a perverse pride in being unprepared for an important lecture, or those who simply complain that students are a waste of their important time. The gendered nature of teaching 'failures' is also extremely important, with students repeatedly giving male staff benefits of the doubt they do not deserve, misreading indifference and lack of teaching ability as signs of genius - if the students cannot understand what is going on, after all, it must be because the academic is operating at some higher level. But most troubling is that frequently such self-induced 'failures' can actually benefit those carrying them out. Teaching, administration, and emotional roles are prime sites of 'strategic incompetence', where people are able to 'fail up' spectacularly, having their time freed up for more research. This is also seen in cases where male staff sexually harass students and/or colleagues, meaning they are removed from certain duties, giving them more time to write, and ultimately benefitting their careers (Mansfield et al., 2019). So once more we must be militant about failure, and discuss it in a way that is supportive and not intimidating, that avoids both self-flagellation and self-aggrandisement, and treats teaching as importantly as it should be. With better reflection on not only failure itself, but also the academy's intersectional political economy, this should be possible.

\section{Conclusion: Can the failure speak?}

Underlying this whole intervention is a paradox. Published papers about failures are, almost by definition, successes (even if lacking high-impact clout). Discussion of failure is often more alluring when done by those who are more successful - it can certainly be more powerful to discover that even prestigious academics struggle. And given the good 
Can the failure speak? Militant failure in the academy

intentions of this turn to failure, it is being discussed more than ever, in articles, at conferences, and in special issues such as this. But what of the academically-subaltern voices we do not hear? I occupy a contradictory position: being a precariously employed academic means I see myself as a failure (academically, at least) compared to those with permanent contracts, but I am also aware of my relative privilege in having a job at all. The move from the real, to an almost total, subsumption of academia means it disciplines even those on the outside looking in. The full-time nature of job-application, and the levels of competition to get them, mean one needs to maintain an 'academic' subjectivity even when outside of academia. There is a huge reserve army of highly skilled but often incredibly unlucky academics. Academia's stresses and anxieties are well documented (Berg et al., 2016; Peake and Mullings, 2019), but they can be more acute and personalised when one is unable to get an academic job. In this situation uncritical talk of failure runs the gamut from self-indulgent to downright offensive. If failure becomes synonymous with resilience then nothing changes, and intersectional structures that privilege certain groups remain. Discourses of failure need to be collective and disruptive. They need to avoid speaking for, and work to open spaces and opportunities to those who are not relative successes. But we must be vigilant. We must be militant. We must frame this discussion as a structural critique of the academy. We must consider the consequences of our writing and presentations. Because when it feels like you are failing to even be a failure, the (emotional) consequences are devastating. 


\section{Bibliography}

Berg LD, Huijbens EH and Larsen HG (2016) Producing anxiety in the neoliberal university. The Canadian Geographer / Le Géographe canadien, 60(2):168-180.

Caretta MA and Jokinen JC (2017) Conflating Privilege and Vulnerability: A Reflexive Analysis of Emotions and Positionality in Postgraduate Fieldwork. The Professional Geographer, 69(2):275-283.

Colectivo Situaciones (2007) On the Researcher-Militant. In: Cote M, Day RJF, and de Peuter G (eds), Utopian Pedagogy: Radical Experiments Against Neoliberal Globalization, Toronto: University of Toronto Press:186-200.

Esson, J. Noxolo, P. Baxter, R. et al. (2017) 'The 2017 RGS-IBG chair's theme: decolonising geographical knowledges, or reproducing coloniality?’ Area. 49(3):384-388.

Graeber D (2018) Bullshit jobs: A theory. New York, NY: Simon and Schuster.

Halberstam J (2011) The Queer Art of Failure. Durham and London: Duke University Press 
Can the failure speak? Militant failure in the academy

Harrowell E, Davies T and Disney T (2018) Making Space for Failure in Geographic Research. The Professional Geographer, 70(2):230-238.

Katz C (2017) Revisiting minor theory. Environment and Planning D: Society and Space, 35(4):596-599.

Klocker N (2015) Participatory action research: The distress of (not) making a difference. Emotion, Space and Society, 17:37-44.

Maddrell A, Thomas NJ and Wyse S (2019) Glass ceilings and stone floors: an intersectional approach to challenges UK geographers face across the career lifecycle. Geografiska Annaler: Series B, Human Geography, 101(1):7-20.

Mansfield B, Lave R, McSweeney K, et al. (2019) It's time to recognize how men's careers benefit from sexually harassing women in academia. Human Geography 12(1):82-87.

Peake L and Mullings B (2019) Mental Health. In: Keywords in Radical Geography: Antipode at 50, Hoboken, NJ, USA: John Wiley \& Sons, Inc:175-180.

Pickerill J (2019) Experimentations. In: Keywords in Radical Geography: Antipode at 50, Hoboken, NJ: John Wiley \& Sons, Inc:118-122.

Pusey A (2018) A cartography of the possible: Reflections on militant ethnography in and against the edu-factory. Area, 50(3):364-371.

Tuck E and Yang KW (2012) Decolonization is not a metaphor. Decolonization: Indigeneity, Education \& Society 1(1):1-40. 